\title{
A STUDY ON HARD PALATE AND HIGH ARCHED PALATE: A MORPHOMETRIC STUDY WITH ASSOCIATED TRAITS
}

\section{Panathula Annapurna ${ }^{1}$, PeruriPushyami *2.}

${ }^{1}$ Assistant professor, Department of Anatomy, Pinnamaneni Siddhartha Medical College, Vijayawada, Andhra Pradesh, India.

${ }^{* 2}$ Assistant professor, Department of Anatomy, Pinnamaneni Siddhartha Medical College, Vijayawada, Andhra Pradesh, India.

\section{ABSTRACT}

Background: The hard palate is important for feeding, mastication and speech. Mammals with a defective hard palate may die shortly after birth due to the inability to suckle. The interaction between tongue and hard palate is essential in the formation of certain speech sounds. In high arched palate, a proper palate-lingual contact is not achieved, resulting in defective articulation. Surgically, the anatomy of hard palate can be modified by using Palatal Height Index measurement, which could lead to the improvisation of palato-lingual contact and articulation. This study aims to determine the Palatal height index.

Results: After taking detail history of the subjects, the qualitative and quantitative parameters were measured and then compared between the normal group $(n=60)$ and high arched palate group $(n=60)$ to know the statistical significance between the two groups. The qualitative parameters measured in this study were shape of hard palate, permanent dentition, microdontia, spacing of teeth, missing of teeth, eruption time of teeth, crowding of teeth, malalignment, and malocclusion. The quantitative parameters measured in this study were average linear width, average height and palatal height index. Impressions of hard palate were taken through the prepared cast. From the prepared cast average linear width, average height and palatine height index were measured. The mean \pm SD value of average linear width measured between two molars was found to be $3.82 \pm 0.32$ in normal and 3.46 \pm 0.17 in high arched palate subjects. The mean \pm SD value of average height measured between two molars was $1.58 \pm 0.26$ in normal and $2.06 \pm 0.2$ in high arched palate subjects. The mean \pm SD value of palatine height index measured between two molars was $41.98 \pm 9.82$ in normal and $59.69 \pm 5.81$ in high arched palate subjects.

Conclusion: Palatal height index was high in the study group when compared to the normal group of similar aged candidates and the results were found to be statistically significant. Crowding of incisors and canines, malocclusion, malalignment, absence of $2^{\text {nd }}$ premolar, spacing of teeth were observed in high arched palate group.

KEY WORDS: Hard palate, Crowding of teeth, Malocclusion, Average linear width, Average height and Palatal Height Index.

Address for Correspondence: Dr.PeruriPushyami, Assistant professor, Pinnamaneni Siddhartha Medical College, Vijayawada, Andhra Pradesh, 521345, Mobile no: 9963175827,

E-Mail: dr.pushyami@gmail.com

Access this Article online

Quick Response code

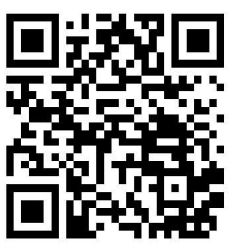

DOI: $10.16965 /$ ijar.2019.198

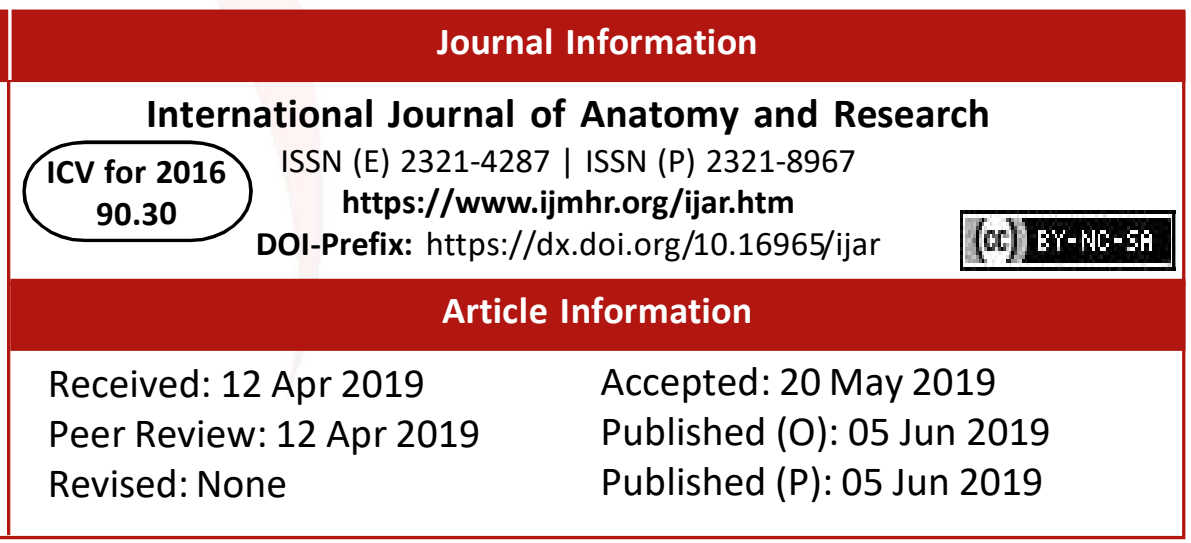

\section{INTRODUCTION}

The oral cavity is separated from the nasal cavity by the palate, which is divided into anterior hard palate and posterior soft palate. The hard palate is made up of bones i.e, maxilla bone in the anterior and palatine bone in the 
posterior part, which are united by palatomaxillary suture [1]. The integrity of the hard palate is crucial in the acquisition of spoken language and healthy development of facial structures. The hard palate is an important structure in speech production. As the uppermost boundary of the oral cavity, it is hypothesized that the hard palate passively influences tongue kinematics [2]. These functions include providing a surface to assist in precise positioning of the tongue during articulation and supplying tactile sensory feedback about the position of the tongue. Gopalan Bhagyalakshmi et al [3] worked on metric analysis of the hard palate in children with Down's syndrome. According to Howell et al [4] Palatal height $>2 \mathrm{~cm}$ is regarded as high arched palate, which is associated with around 300 different conditions and can lead to a range of difficulties, including disrupted sleep caused by obstruction of the nasal passages, speech problems, and abnormalities in head and neck. The condition is also associated with dental problems later in life, such as crowding of teeth[5].

Many studies have been done to compare the palatal dimensions between Class I and Class II malocclusion, normal occlusion and different malocclusion, normal subjects and subjects with Turner's syndrome, normal subjects and subjects with Down's syndrome, thalassemic patients and normal subjects, monozygotic and dizygotic twins and subjects with open bite, deep bite and normal occlusion. On the other hand, two studies were conducted to establish the palatal index and compare it in primary, mixed and permanent dentitions. The aim of study is to know the detailed history of patients including qualitative and quantitative measurements and compare the measurements between normal group and high arched palate group to know the statistical significance.

\section{MATERIALS AND METHODS}

The patients attending the OPD of Government Dental College and Hospital, Vijayawada between the years 2013 and 2018 were examined with the support of dental surgeons. 120 subjects were recruited in the study from the age of 15 to 18 years i.e. 60 subjects with normal hard palate and 60 subjects with high arched palate were compared and evaluated using specific indices. Institutional ethical committee approval was obtained. The consent of each patient was taken. The subjects based on the following inclusion and exclusion criteria were recruited for the study.

Inclusion criteria: All subjects (age between 15-18yrs) had complete permanent dentition regardless the third molars, Subjects with each tooth intact in structure, without any fracture, caries, trauma or heavy restoration

Exclusion criteria: Subjects withTeeth subjected to attrition and abrasion, Unhealthy gingival tissue with no gingivitis or periodontitis or any gum recession, Any previous history of significant medical disease or trauma. Previous orthodontic, prosthetic or surgical treatment

Equipment's used in the study include Dental mirrors, dental probes, kidney tray, antiseptic solution (dettol), cotton, perforated plastic trays, rubber bowl, wide bladed plastic spatula, measurement scoop for measuring alginate and stone, irreversible hydrocolloid impression material (alginmax), dental stone, plaster of paris, rubber mould base, modelling wax, sharp lead pencil, rulers, digital vernier calliper (sensitivity: $0.01 \mathrm{~mm}$ ) and wheel trimmer.

\section{Procedure:}

Each subject was asked to sit comfortably in the dental chair and personal and medical history such as name, age, origin, history of facial trauma and orthodontic treatment etc., were recorded. Then, they were asked to look forward horizontally in the Frankfurt's plane and a dental impression was taken. A dental impression is a negative imprint of hard (teeth) and soft tissues in the mouth from which a positive reproduction can be formed. These impressions were made by using trays which roughly fit the dental arches. The impressionable materials weresemi-solid when first mixed and placed in the tray. To acquire an imprint of the structures of the mouth, the tray was then placed in the desired area to set to a solid.

Impression Making and Cast Preparation method:Impressions were made from every subject with alginate impression material and filled with a prepared amount of dental stone. After setting of the dental stone, a base of 
plaster of paris was prepared, and then the cast was inverted over it. After the final setting of the gypsum, the base was trimmed uniformly by trimmer and made ready for the measuring procedure (Figure 1). The features of normal palate and high arched palate were observed and noted.

Evaluation Methods:The following data were noted from each subject: name, age, sex, shape of hard palate, number of teeth, microdontia, spacing of teeth, missing teeth, dental caries, time of eruption of teeth, crowding of teeth, malalignment, malocclusion, tongue surface, tone, and size, forehead, eyebrows, eyes, ear, lips, growth of mandible and nasal bridge.

From the prepared cast, average linear width and average height was measured between the molars, pre molars, canines and incisors. Then, by using these two parameters, the palatine height index was calculated.

Average linear width: It is the linear measurement taken from the gingival margin of one tooth to the corresponding tooth on the opposite side of maxilla. Average linear width was measured by Vernier calliper in control and high arched palate cast (Figure 2).

Average height: Average height in normal and high arched palate cast was measured using long scale and modelling wax. The height was measured from the midpoint of average linear width to midpoint of the average curvilinear width. The procedure was repeated and the average of the two readings was recorded as the average height in each plane (Figure 3 ).

Palatal Height Index: It was calculated by the ratio between the maximum palatal height and the maximum palatal width.

Palatal height index $=$ maximum palatal height / maximum palatal width $\times 100$

Statistical analysis:The present study is a crosssectional observational study. Average linear width, average height and palatal height index of both high arched and control groups were measured in different planes and the values obtained were tabulated as mean \pm standard deviation and student t- test was applied. Palatal values of high arched palate subjects were compared with reference values by a two-tailed student t-test for independent samples. The level of significance of 5 percent $(P<0.05)$ was set for all analysis.

Fig. 1:Showing the cast preparation method.

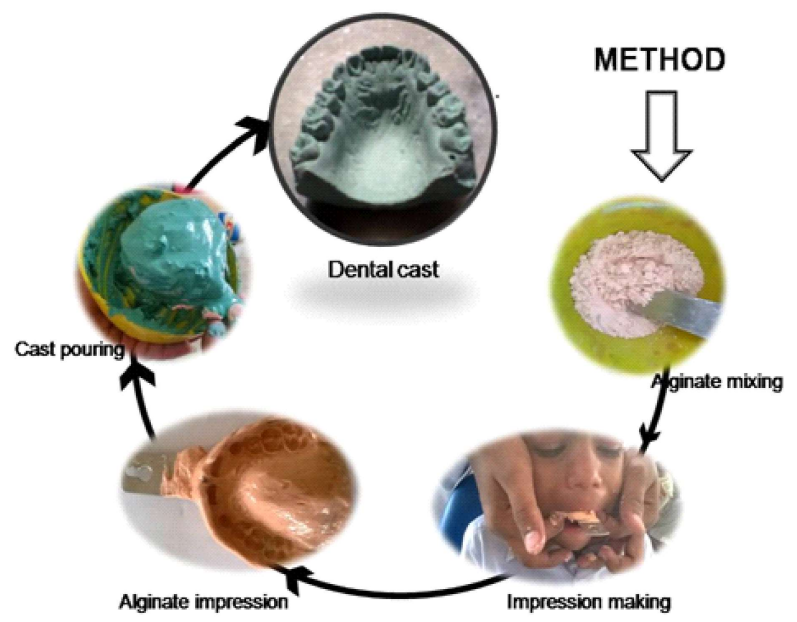

Fig. 2:Showing the average linear width between two molars.

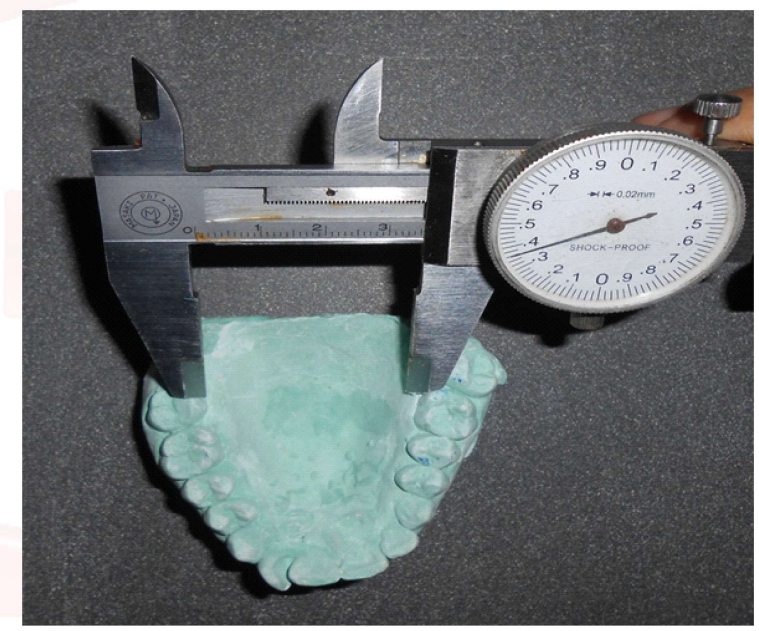

$\mathrm{Cl}=$ Central Incisor, $\mathrm{LI}=$ Lateral Incisor, $\mathrm{C}=$ Canine, $\mathrm{PM} 1=1$ st Premolar, $\mathrm{PM} 2=$ 2nd Premolar. $\mathrm{M} 1=1$ st Molar, $\mathrm{M} 2=$ 2nd Molar.

Fig. 3: Showing the average height between two molars.

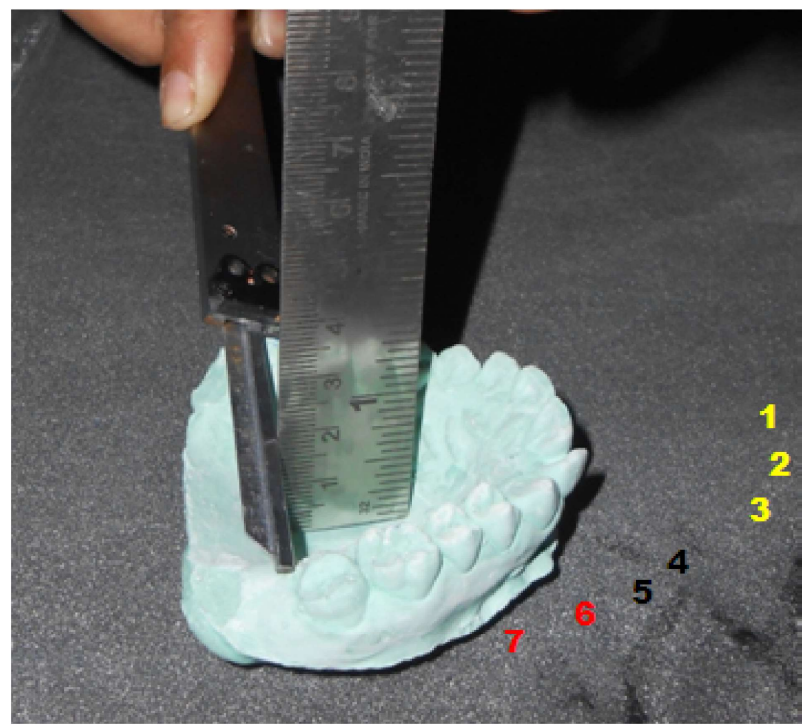

1 - Central incisor, 2 -Lateral incisor, 3 - Canine, 4 -1st Premolar 5 - 2nd Premolar, 6 - 1st Molar, 7 - 2nd Molar 


\section{RESULTS}

Table 1: Showing the measurements of Average linear width at different planes.

\begin{tabular}{|c|c|c|c|c|c|c|}
\hline Average linear width & Group & Sample size (n) & $\begin{array}{c}\text { Mean in } \\
\mathrm{cms}\end{array}$ & SD in $\mathrm{cms}$ & p value & Inference \\
\hline \multirow{2}{*}{ between 2 molars } & control & 60 & 3.82 & 0.32 & \multirow{2}{*}{$p<0.0001$} & \multirow{2}{*}{$\begin{array}{c}\text { Highly } \\
\text { significant }\end{array}$} \\
\hline & High arched & 60 & 3.46 & 0.17 & & \\
\hline \multirow{2}{*}{ between 2nd pre molar } & control & 60 & 3.32 & 0.11 & \multirow{2}{*}{$p<0.0001$} & \multirow{2}{*}{$\begin{array}{c}\text { Highly } \\
\text { significant }\end{array}$} \\
\hline & High arched & 60 & 3.07 & 0.26 & & \\
\hline \multirow{2}{*}{ between 1st pre molar } & Control & 60 & 2.73 & 0.106 & \multirow{2}{*}{$p<0.05$} & \multirow{2}{*}{ Significant } \\
\hline & High arched & 60 & 2.58 & 0.314 & & \\
\hline \multirow{2}{*}{ between canines } & control & 60 & 2.18 & 0.46 & \multirow{2}{*}{$p>0.05$} & \multirow{2}{*}{$\begin{array}{c}\text { Not } \\
\text { significant }\end{array}$} \\
\hline & High arched & 60 & 2.23 & 0.302 & & \\
\hline \multirow{2}{*}{ Between lateral incisors } & control & 60 & 1.92 & 0.379 & \multirow{2}{*}{$p<0.05$} & \multirow{2}{*}{ Significant } \\
\hline & High arched & 60 & 1.71 & 0.284 & & \\
\hline \multirow{2}{*}{ Between central incisors } & control & 60 & 0.82 & 0.048 & \multirow{2}{*}{$p>0.05$} & \multirow{2}{*}{$\begin{array}{c}\text { Not } \\
\text { significant }\end{array}$} \\
\hline & High arched & 60 & 0.81 & 0.103 & & \\
\hline
\end{tabular}

Table 2: Showing the measurements of Average height at different planes.

\begin{tabular}{|c|c|c|c|c|c|c|}
\hline Average height & Group & $\begin{array}{c}\text { sample } \\
\text { size(n) }\end{array}$ & $\begin{array}{c}\text { Mean in } \\
\mathrm{cms}\end{array}$ & SD in $\mathrm{cms}$ & p value & Inference \\
\hline \multirow{2}{*}{ between 2 molars } & control & 60 & 1.58 & 0.262 & \multirow{2}{*}{$p<0.0001$} & \multirow{2}{*}{$\begin{array}{c}\text { highly } \\
\text { significant }\end{array}$} \\
\hline & high arched & 60 & 2.06 & 0.2 & & \\
\hline \multirow{2}{*}{ between 2nd pre molar } & control & 60 & 1.77 & 0.15 & \multirow{2}{*}{$p<0.0001$} & \multirow{2}{*}{$\begin{array}{c}\text { highly } \\
\text { significant }\end{array}$} \\
\hline & high arched & 60 & 2.29 & 0.19 & & \\
\hline \multirow{2}{*}{ between 1st pre molar } & control & 60 & 1.76 & 0.224 & \multirow{2}{*}{$p<0.0001$} & \multirow{2}{*}{$\begin{array}{c}\text { highly } \\
\text { significant }\end{array}$} \\
\hline & high arched & 60 & 2.11 & 0.1 & & \\
\hline \multirow{2}{*}{ between canines } & Control & 60 & 0.93 & 0.18 & \multirow{2}{*}{$p<0.0001$} & \multirow{2}{*}{$\begin{array}{c}\text { Highly } \\
\text { significant }\end{array}$} \\
\hline & high arched & 60 & 1.58 & 0.46 & & \\
\hline \multirow{2}{*}{ between lateral incisors } & Control & 60 & 0.58 & 0.082 & \multirow{2}{*}{$p<0.0001$} & \multirow{2}{*}{$\begin{array}{c}\text { Highly } \\
\text { significant }\end{array}$} \\
\hline & high arched & 60 & 0.79 & 0.123 & & \\
\hline \multirow{2}{*}{ between central incisors } & Control & 60 & 0.46 & 0.1 & \multirow{2}{*}{$p>0.05$} & \multirow{2}{*}{$\begin{array}{c}\text { Not } \\
\text { significant }\end{array}$} \\
\hline & high arched & 60 & 0.46 & 0.14 & & \\
\hline
\end{tabular}

Table 3: Showing the measurements of Palatal Height Index at different planes.

\begin{tabular}{|c|c|c|c|c|c|}
\hline Group & Sample size $(\mathbf{n})$ & Mean & SD & p value & Inference \\
\hline control & 60 & 41.98 & 9.82 & \multirow{2}{*}{0.0001} & $\begin{array}{c}\text { Highly } \\
\text { significant }\end{array}$ \\
\hline high arched & 60 & 59.69 & 5.81 & & \\
\hline
\end{tabular}

In high arched palate subjects, the shape of the hard palate was found to be narrow, constricted and relatively higher in all the 60 cases. Permanent dentition was observed in 56 cases. In the present study, microdontia and spacing of teeth was observed in 4 cases. Absent $2^{\text {nd }}$ premolar in 4 cases. The eruption time was found to be within normal limits. Crowding of incisors and canines has been seen in 14 cases among the 60 cases examined.Malalignment and malocclusion was found to be present in 8 cases only. No abnormality was observed in tongue, forehead, eyebrows, eyes, ear, lips, growth of mandible and nasal bridge.
Quantitative measurements:The average linear width, average height and palatal height index were measured from the impressions of the dentopalatine cast.

Average linear width: The two tail student $t-$ test was applied and the standard deviation, range, $t$-value and $p$-value at different planes were analysed. Average linear width mean values of the high arched group were observed to be less than the mean values of the control group and the results were found to be statistically significant (Table 1 ).

Average height: The mean values of the high arched group were observed to be greater than 
the mean values of the control group and the results were found to be statistically significant (table 2).

Palatal Height Index: The mean value of the high arched group was observed to be greater than the mean values of the control group and the results were found to be statistically significant (Table 3).

\section{DISCUSSION}

According to study done by Gopalan Bhagyalakshmi et al [3] the average linear width measurements in high arched palate subjects between two molars was $3.53 \mathrm{cms}$, which was slightly higher than the present study findings i.e., $3.46 \mathrm{cms}$. A study done by Bresolin et al[6] in high arched palate, average linear width between two molars was found to be $3.31 \mathrm{cms}$, which is slightly lower than the current study findings. The current study findings are similar to the findings of Bagic I et al [7], which had $3.46 \mathrm{cms}$ between the two molars in the high arched palates of Down's syndrome subjects.

The average height measured between two molars in the current study is $2.06 \mathrm{cms}$, which is higher than Gopalan Bhagyalakshmi et al [3] i.e., $1.2 \mathrm{cms}$ and is only slightly lesser than the findings of Bresolin et al [6] which was $2.11 \mathrm{cms}$. A slightly lower values than the current study were reported by Howell et al[4] which was $2.01 \mathrm{cms}$ and Panchon-Ruiz et al[8], which was $2 \mathrm{cms}$.

According to the studies conducted by Camilla Mulazzani et al[9], the palatal height index was 52.9 and that of Hassanali et al[10] was 56, which were lower in comparison to the value obtained from this study i.e., 59.69.

In our study the palate was found to be narrow and constricted in the high arched palate subjects, while a narrow, elliptic paraboloid and shelf like palates were recorded in Down syndrome subjects with high arched palate [8, 11 \& 12].

The shape and height of the palate can have an influence on the musculature of the palate. The defective contraction of the tensor veli palatini muscle, which is attached from the eustachian tube to the palate can produce a patulous eustachian tube resulting in increased frequency of middle ear infections[13]. The palatal vault height is increased in high arched palates, which can be seen due to congenital causes like Down syndrome, Crouzon syndrome, Apert syndrome etc, or can be because of acquired causes like thumb sucking. The high arched palate reduces the volume of the nasal cavity causing an increase in turbulence to the air conduction. This may lead to the increased incidence of infections and carcinomas of the nasal and nasopharynx regions due to the increased deposition of air borne particles and microorganisms[14]. The variation in height of the palate along with reduced area is also implicated in sleep disorderd breathing, which could be due to palatopharyngeal insufficiency in normal and preterm babies[15]. The findings in the present study may encourage orthodontic surgeries for the high arched palate patients and also anthropometry of the face and intraoral regions can help in the field of forensic odontology when common forensic data is unavailable.

\section{CONCLUSION}

The present study was done in 60 normal and 60 high arched palates of male individuals aged between 15-18 yrs. The mean value of the palatal height index in the high arched group was observed to be greater than that of the control group and the results were found to be statistically significant.

Among the 60 high arched cases examined under this study, qualitatively; Crowding of incisors and canines had been found in 14 cases, malalignment and malocclusion noticed in 8 cases, microdontia in 4 cases, spacing of teeth in 4 cases and absent $2^{\text {nd }}$ premolar in 4 cases have been observed.

\section{ACKNOWLEDGEMENTS}

I offer my sincerest gratitude to Prasad, statistician, Siddhartha. Medical college, Vijayawada for his contribution to the statistical analysis of this article. Also, I would like to thank Dr. Raj Kiran, Asst professor, Dept. of Anatomy, SVMCH, Puducherry for his guidance in preparing the manuscript. I am grateful for the subjects, who participated and contributed for this study, without whom it would not have been possible.

\section{Conflicts of Interests: None}




\section{REFERENCES}

[1]. Standring S. Gray's anatomy: The anatomical basis of clinical practice. $40^{\text {th }}$ Ed. 2016; Churchill Livingstone, Elsevier, Edinburgh, London.

[2]. Antony Sylvan D Souza, Mamatha H, Nayak Jyothi. Morphometric analysis of hard palate in South Indian skulls. Jour of Biomedical research 2012; 23(2):173-175.

[3]. Bhagyalakshmi G, Renukarya AJ, Rajangam S. Metric analysis of the hard palate in children with Down syndrome: a comparative study. Downs Syndr Res Pract. 2007 Jul; 12(1):55-9.

[4]. Howell S. Assessment of palatal height in children. Community Dentistry and Oral Epidemiology. 1981; Feb 9(1):44-47.

[5]. Amanymohammed, Farak. Palatal dimensions in different races. American Jour. of Orthodontics. 2013; 15: 29-33.

[6]. Bresolin, McFarland DH. Speech adaptation to an artificial palate. Jour of the Acoustical Society of America. 2005; 102(4): 2353-59.

[7]. Bagic I, Verzak Z. Craniofacial anthropometric analysis in Down's syndrome patients. Collegium Antropologicum. 2003; 27:23-30.

[8]. Panchón-Ruiz A, Jornet-Carrillo V, Sanchez del Campo F. Palate vault morphology in Down syndrome. J Craniofac Genet Dev Biol. 2000 Oct-Dec; 20(4):198200.
[9]. Maria CM, da Silva AM, Stella Angela RB, de Paula GB, Berwig LC. Evaluation of hard palate depth: Correlation between quantitative and qualitative method. Rev CEFAC. 2013;15: 1292-99.

[10]. Hassanali J, Mwaniki D. Palatal analysis and osteology of the hard palate of the Kenyan Africanskulls. Jour of Anatomical Research. 1984; 209: 273-280.

[11]. Skrinjariæ T, Glavina D, Jukiæ J. Palatal and dental arch morphology in Down syndrome. Coll Antropol. $2004 \mathrm{Dec} ; 28(2): 841-7$.

[12]. Abeleira MT, Outumuro M, Diniz M, Limeres J, Ramos I, Diz P. Morphometry of the hard palate in Down's syndrome through CBCT-image analysis. OrthodCraniofac Res. 2015 Nov; 18 (4):212-20.

[13]. Kim SJ, Donovan DM, Blanchard SB, Kowolik JE, Eckert GJ. The relationship between acute otitis media and the anatomic form of the hard palate. Pediatr Dent. 2008 Jan-Feb; 30(1):9-14.

[14]. Das S, Gupta T, Dholam K, Chouksey G, Ghosh Laskar $\mathrm{S}$, Prakash Agarwal J. Is palatal vault height a determinant for nasopharyngeal carcinoma: A hypothesis? Med Hypotheses. 2015 Nov; 85(5):534-6.

[15]. Huang YS, Hsu JF, Paiva T, Chin WC, Chen IC, Guilleminault C. Sleep disordered breathing, craniofacial development, and neurodevelopment in premature infants: a 2-year follow-up study. Sleep Med. 2018 Oct 29. pii: S1389-9457(18)30872-4.

How to cite this article:
Panathula Annapurna, PeruriPushyami. A STUDY ON HARD
PALATE AND HIGH ARCHED PALATE: A MORPHOMETRIC STUDY
WITH ASSOCIATED TRAITS. Int J Anat Res 2019;7(2.3):6657-6662.
DOI: $10.16965 /$ ijar.2019.198 